\title{
Restoration of Murals of the National Museum of Antiquities of Tajikistan
}

\author{
Rukhayyo Karimova*
}

Faculty of History and International Relations, Russian-Tajik Slavonic University, 30 M. Tursunzoda St., Dushanbe, 734025, Tajikistan

\begin{abstract}
The paper analyses traditional and modern methods and technologies for preservation and restoration of wall paintings found through archaeological excavations in the Republic of Tajikistan. Medieval monuments such as the ancient Panjekent, Bundzhikat, Adzhina-Tepa and others gave a variety of works of pictorial art, including unique monumental paintings, the preservation of which presents a priority task for scientists, restorers and art experts. These artefacts are exposed in the State Hermitage Museum (St. Petersburg), the National Museum of Antiquities of Tajikistan, the Republican Museum of History and Local Lore of Rudaki in Penjikent and the National Museum of Tajikistan. The paintings portray diverse and interrelated household, mythological, religious and epic plots, battle scenes, scenes of feasts and hunting, as well as geometrical, vegetable, and zoomorphic motives. The study of these paintings helps scientists to study in detail the medieval history of Tajik people. Therefore, their preservation is the primary task of the corresponding experts. The paper is based on personal experience of the author in preservation and restoration of monumental paintings within international projects on preservation of cultural heritage of Tajik people.
\end{abstract}

\section{Introduction}

At present, the society is facing an urgent need to preserve the objects of historical and cultural heritage, which are destroyed throughout time or as a result of human activity. Mural paintings in medieval architecture of the Central Asia are fairly considered an important part of the world art culture. The ancient cities Panjekent and Bundzhikat, and the Buddhist monastery AdzhinaTepa are preliminary included into the UNESCO World Heritage List to promote their visibility and preserve them for future generations.

In the framework of archaeological practice, the wall paintings of antiquity and the Middle Ages are considered as 'especially valuable category of artefacts'. Each found painting becomes an important subject of study within the Central Asian fine arts [1]. Archaeological findings in Panjekent, Shakhristan, Adzhina-Tepa and other monuments opened up magnificent multigenre wall painting, including narrative and ornamental paintings. Heroism and fantasy, battle scenes, hunting, feasts, sketches from ancient legends, etc. were the most frequently plotted on such paintings. Wall painting was developing following local and Hellenistic traditions, which were adopted in the Central Asia from the Hellenistic Syria, Coptic Egypt and some eastern centers of Graeko-Roman civilization.

The study presents an attempt to identify features of wall painting found in Tajikistan, as well as to make a general conclusion regarding the main modern technical and technological methods of restoration and preservation of the monumental art.

The study is based on historical, descriptive, and comparative methods.

First of all, it should be noted that traditionally the monumental painting is called a 'fresco painting', however unlike fresco painting, which is performed on crude plaster (from ital. fresco - fresh), the wall painting in the Central Asia is made on dry loessial plaster and is called 'a secco' (from ital. a secco - on dry). The paints contain mineral and plant pigments based on vegetable mucilage serving a binding agent. In this regard, it should be noted that the 'a secco' technique is not durable: under the influence of atmospheric factors, low and high temperatures, as well as salty soils and human activity the ink coat is peeled off from the basis. Thus, the restorers face certain difficulties when preserving the works of art.

\section{Results and Discussions}

The study of monumental wall painting in Tajikistan started in the middle of the 20th century when, in 1946 the group of archeologists led by experts from the State Hermitage Museum began excavation works in the ancient city Panjekent. The excavation is still on-going. The ancient city Panjekent represents a complex monument. It consists of an extensive ark with three strengthening pillars, the Shakhristan city surrounded by

\footnotetext{
Corresponding author: ruhayo@mail.ru
} 
a defensive wall, as well as suburban houses and a necropolis.

Archaeological expeditions in Panjekent revealed a large variety of cultural artefacts impressively portraying the routines of citizens of the ancient city. People shall not underestimate the art memorials of the ancient Panjekent presenting a special value for the history of the Central Asian people. They illustrate the outstanding culture of the Sogdians that were the ancestors of Tajik people [2].

The researchers are extremely interested in a marvellous monumental painting, which was found during archaeological excavations on a monument (Fig. 1). Throughout 70 years of excavations in Panjekent, which is often referred to as the Pompeii of the Central Asia, the walls of over 30 out of 150 buildings turned to be painted with glue paints on loessial plaster (Fig. 3). The paintings are found in the ruler's palace, in temples, in dozens of houses of the noblemen, and sometimes in the houses of the middle-class citizens. The quality of paintings did not depend on the customer's social status: the artists always made their paintings highly professional [3]. "The palace halls and corridors, as well as houses were decorated with paintings, which were quite often damaged by violators or fire" [4], nevertheless, they were perfectly preserved until now. Archeologists realized that to preserve these unique paintings under the scorching sunshine and, more importantly, in salty soils was only possible if the paint layer was fixed in situ and then removed from walls and placed in museum storage conditions (Fig. 2).

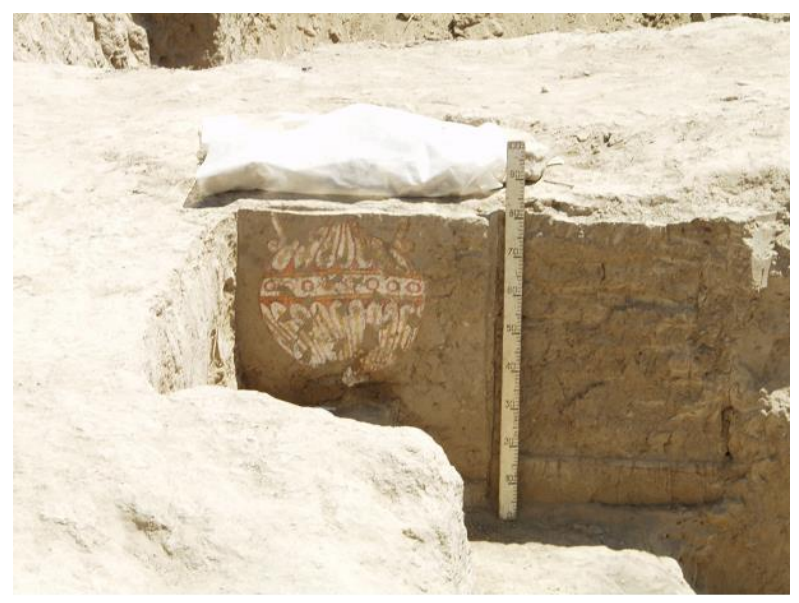

Fig. 1. Wall painting. Ancient city Panjekent.

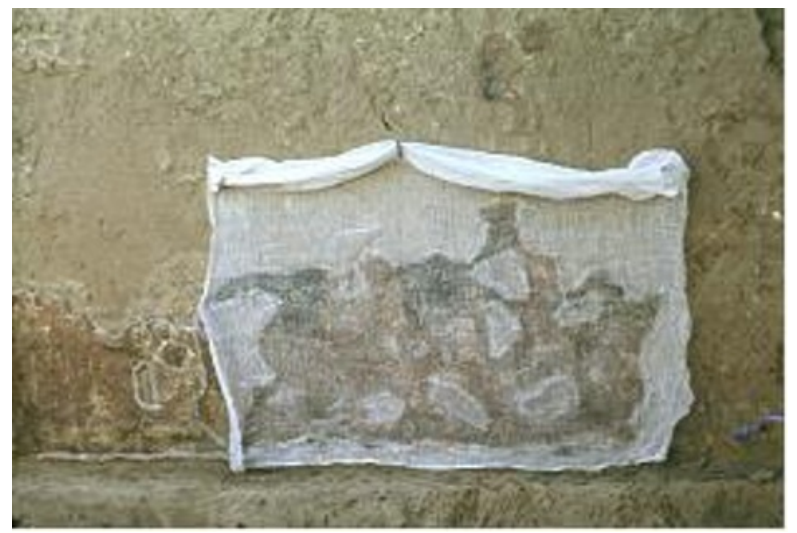

Fig. 2. Removal of wall painting. Ancient city Panjekent.

The group of experts from the Hermitage restoration workshop of easel painting led by P.I. Kostrov was trying to solve this problem. For reference, in 1949 P.I. Kostrov, having studied the monument, began to look for ways and materials to fix a glue painting on porous loessial plaster. "Thus, the method to restore painting from archeological excavations based on synthetic polymer of polybutylmethacrylate (PBMA) was established in late 1940s. Low-viscous PBMA has the necessary properties of restoration material. It is colourless, light-resistant, chemically inert, resistant to aging, has sufficient adhesion, and is dissolved in organic solvents of various classes. But most importantly, the fixing of PBMA is reversible, and the reversibility does not change over time" [5], which is critical for restoration.

The majority of paintings was removed for restoration to the Hermitage where it consitutes one of its expositions - the so-called Blue Hall of Panjekent. Other fragments were kept in the National Museum of the Republic of Tajikistan and were restored in 2000 to become part of the exposition in the new National Museum of Antiquities of Tajikistan, which was opened in 2001. PBMA was also used for their restoration, however for decades the restoration method using this acrylate was improved alongside with the mounting technique. Now the method applies the wooden framework and usees foam plastic, PVA glue and construction foam.

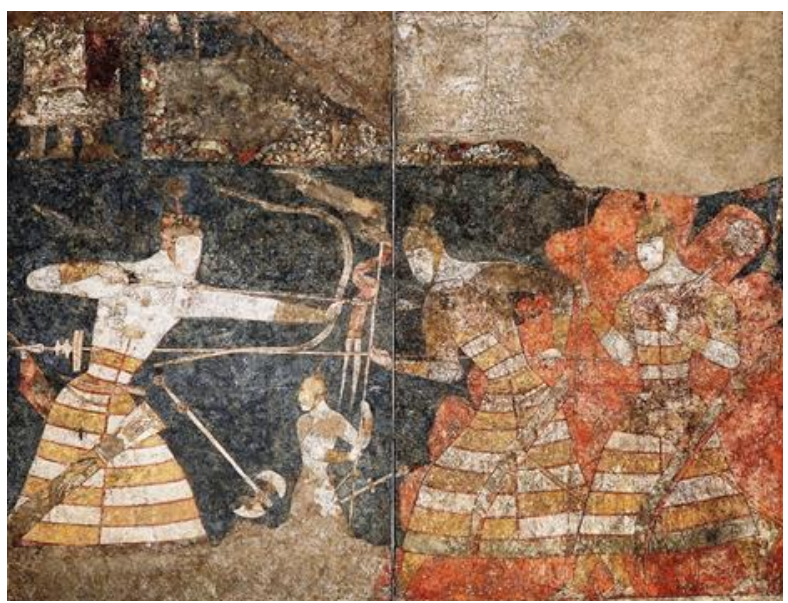

Fig. 3. Wall painting. Ancient city Panjekent.

It should be noted that in 2000 PBMA was applied during restoration of a 13-meter statue of Buddha in nirvana being the largest in the Central Asia. In 2014 the fragment of wall painting portraying a battle scene from Panjekent was also restored using PBMA. However, the restorers noticed that with excessive use of PBMA the paint layer gets darker over time, which in general does not detract from the merit of this acrylate.

The outstanding examples of the Central Asian art include wall paintings found during excavations of the Ustrushana rulers' palaces in the ancient Kalai Kakhkakh I (Bundzhikat) destroyed and burned by Arab conquerors in the 9th century. The unique painting was 
much destroyed here: many fragments were found in the ruins and were slightly deformed under high temperatures. Besides, in the same Panjekent, the painting was damaged in some places by fungi and calcium salt evaporations thus causing the peeling of a plaster surface layer or a paint layer. It was obvious that the restoration would be extremely difficult and will require solid experience and time. In 2008, the Tokyo National Research Institute of Cultural Properties and A. Donish Institute of History, Archeology and Ethnography of the Academy of Sciences of the Republic of Tajikistan concluded the bilateral agreement and started restoration of wall paintings, which were long stored in the National Museum of Antiquities of Tajikistan. The foreign experts from France, Germany, and Italy also participated in the project [6].

The wall painting from the ancient Kalai of Kakhkakh I was chosen as one of restoration objects. The excavation of the palace was carried out in 19651972 by the North-Tajik archaeological group of A. Donish Institute of History, Archeology and Ethnography led by academician N. Negmatov. The paintings found in ceremonial rooms and halls of the palace make it possible not only to highlight the level of cultural development of that period, but also to considerably expand the understanding of monumental art of the entire region, to get a full picture of the Central Asian palace painting in the early Middle Ages.

Due to weak material and technical facilities of the laboratory, new equipment and tools necessary for conservation were delivered from Japan. To define the chemical composition and structure of paints the samples were sent to Japan for further analysis. The newest Japanese photography equipment Nikon with ultra-violet and infrared lamps was also used to identify some specific features of paintings. It is important to emphasize that the photofixation of all processes constitutes an integral part of all restoration works. All these data are then included into the restoration protocols for permanent storage.

The analysis of fragment structures showed that a plaster and a paint layer became brittle and friable, and some pigments lost their color and began to segregate. Thus, for example, the green color turned gray, and in places of especially strong burning it became almost black (obviously due to the reason that vegetable pigments are less resistant than mineral ones). The Japanese experts slightly modified and changed the technology thus improving the quality of restoration. The improved types of acrylates such as Primal E330S and Primal AC2235, as well as Paraloid B72 were applied instead of PBMA, which was earlier used for fixing and patching of fragments.

The mounting of wall painting from Bundzhikat was carried out using advanced materials and technologies that made the mounting stronger and at the same time easier (Fig. 4). Synthetic (epoxy) resin and the strongest carbon fiber were used in mounting (Fig. 5). It should be noted that due to high tensile strength and low specific weight, the carbon fiber is used in aircraft industry, including such large companies as Boeing and Airbus [7, $8]$.

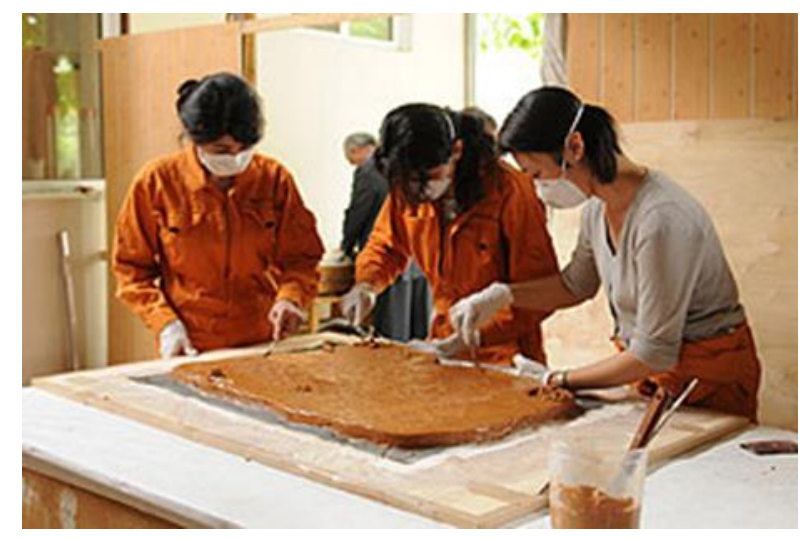

Fig. 4. Mounting of a wall painting.

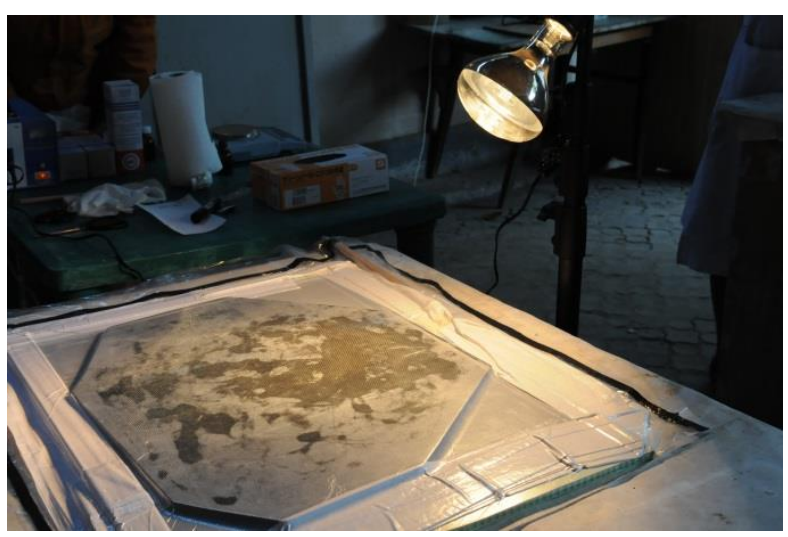

Fig. 5. Mounting. Carbon fiber.

The advanced technologies provided for repeated restoration of some monumental paintings since the main task of museum restoration is not only to ensure safety of exhibits, but also to make them fit for exposition purposes. Hence, it was decided to restore fragments of wall painting in Bundzhikat, Panjekent, Adzhina-Tepa for the second time, which were earlier exhibited in the museum.

First the experts checked the quality of mounting. Next it was decided to clean the painting, which was extremely labor-intensive since it includes the removal of old fixing materials (PBMA) and loessial layers from the paint layer using distilled water, acetone and xylol. Then the old dark mastic was removed. When the fragments were cleared off and prepared for further restoration, the restoration of lost fields was made: new masticising was carried out in neutral color not interfering with the general view of the painting. To ensure the necessary structure, color and strength of mastic the sand, shredded pumitsit, glass microballs (microscopic glass balls filled with air, which get even into the smallest cracks and fill them), as well as various dry pigments (coal or raw umber, chalk, etc.) were mixed with 15\% Primal E330S loess. As a result, the repeated restoration improved the general condition and exposition outlook of fragments (Fig. 6). 


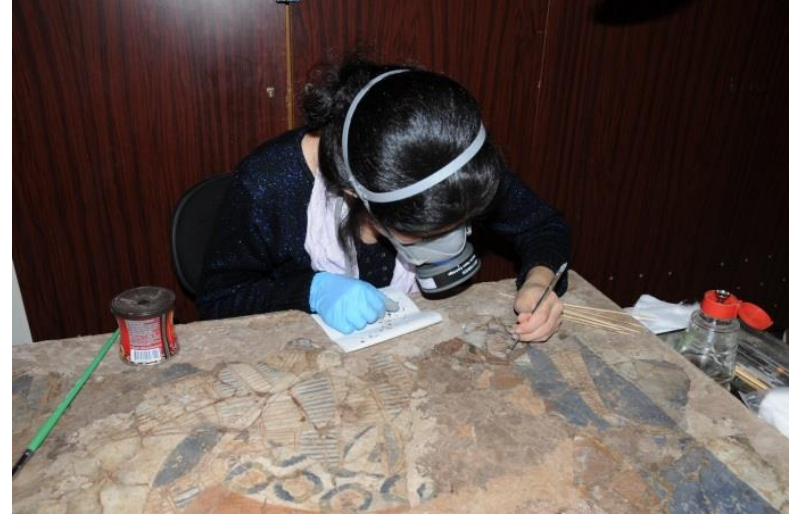

Fig. 6. Restoration. Masticing of a wall painting.

\section{Conclusion}

In order to promote the exchange of experience related to preservation of wall paintings the National Museum of Antiquities of Tajikistan hosted three international workshops devoted to the preservation of wall painting in the Central Asia [9], which besides the group of restorers from Japan, France, Italy, Germany and Tajikistan, attracted the experts from Russia (State Hermitage Museum), Kazakhstan, Kyrgyzstan, Turkmenistan, Uzbekistan and China. These workshops were very fruitful. First of all, they promoted the exchange of experience between the leading experts from Japan, Europe and Russia. They were also able to highlight the importance of restoration training of specialists since the expertise in this particular field is rather limited in all republics of the Central Asia. It was pointed out that the new generation of restorers, which adopted the experience of past generations and improved their knowledge, shall undertake further work on the preservation of the Sogdian monumental art launched in the last century.

In conclusion it shall be noted that the territory of Tajikistan is fraught with unique monuments of cultural heritage being under threat. People shall not forget that this priceless heritage is the province of not only the Tajik people but of all mankind. Therefore the preservation and restoration of these monuments is critical for the state and the public.

\section{References}

1. R. Karimova, Merosi niegon. Restoration of wall painting in Shakhristan (preservation of cultural heritage of the Tajik people), 13, 204-208 (2010)

2. Report of the activities carried out in 2008 by NRICP, 34 (2009)

3. National museum of antiquities of Tajikistan (2006)

4. D. Sultanova, Young scientist. Appearance and interrelation of monumental painting in traditional architecture of Central Asia, 12, 710-719 (2012)

5. Panjekent paintings of the Blue Hall, Retrieved from: https://www.hermitagemuseum.org/wps/portal/hermi tage/what-son/temp_exh/2015/blue hall_paintings/?lng=ru.

6. R. Karimova, Sociocultural relations of Tajikistan and Japan. Thesis. Manuscript (2009)

7. Japan's international cooperation in heritage conservation. Conservation of wall painting fragments in the collection of the National museum of antiquities of Tajikistan, 14 (2011)

8. Panjekent paintings of the Blue Hall. Retrieved from: https://www.hermitagemuseum.org/wps/portal/hermi tage/what-s-

on/temp_exh/2015/blue_hall_paintings/?lng=ru

9. E. Kageyama, Conservation of Wall Paintings Fragments in Tajikistan and Capacity Development (9 $9^{\text {th }}$ Mission). Retrieved from: http://www.tobunken.go.jp/materials/ektauthor/kagey ama-etsuko

10. Removal of damaging conservation treatments on mural paintings $\mathbf{7 2}$ (2007)

11. Japan's international cooperation in heritage conservation. Conservation of wall painting fragments in the collection of the National museum of antiquities of Tajikistan, 14 (2011)

12. Report of the activities carried out in 2008 by NRICP, 59 (2008)

13. Report of the activities carried out in 2008 by NRICP, 4 (2010)

14. Bulletin of EXPO - 2005, Aichi, Japan. Great Silkroad, (Central Asia Pavilion, 2005) 